\title{
The Effects of School Closures on COVID-19: A Cross-Country Panel Analysis
}

\author{
Vincenzo Alfano ${ }^{1,2}$ (1)
}

Accepted: 16 November 2021 / Published online: 10 December 2021

(C) The Author(s), under exclusive licence to Springer Nature Switzerland AG 2021

\begin{abstract}
Background There has been much debate about the effects and importance of closing, keeping closed, or not opening schools in order to prevent COVID-19 contagion. This policy has been questioned regarding both its efficacy and the social cost it entails, including the possible asymmetric impact it has on genders in many societies due to traditional childcare roles. To the best of our knowledge no existing contribution has attempted to gauge the effectiveness of such a policy over time, in a longitudinal cross-country perspective.

Objectives This paper aimed to fill the gap in the literature by assessing, at a European level, the effect of school closures (or the lack of such measures) on the numbers of new COVID-19 infections, in the absence of vaccines. Given this policy's expected change in effectiveness over time, we also measured the effectiveness of having schools closed after a given number of days (from 7 to 100). Methods We pursued our objectives by means of a quantitative panel analysis, building a longitudinal dataset with observations from countries in Europe, from 1 January to 30 September, and estimating the impact of school closure via feasiblegeneralised least-squares fixed effect and random effect estimators, and analysis of variance (ANOVA) mixed models.

Results Our results show that having schools closed is effective in reducing the number of new cases. Countries that implement closure have fewer new COVID-19 cases than those that do not. This becomes a reality around 20 days after the implementation of the policy. Its efficacy continues to be detectable up to 100 days after implementation. The result is robust to controls for other forms of social distancing.

Conclusion Results suggest that school closure is effective in reducing the number of people who are infected with COVID19. Unlike what has been suggested in previous analyses or with regard to other diseases, its efficacy continues to be detectable up to 100 days after the introduction of the policy.
\end{abstract}

JEL Classification $\mathrm{H} 51 \cdot \mathrm{H} 75 \cdot \mathrm{I} 18$

\section{Key Points for Decision-Makers}

School closures are effective in reducing the number of new COVID-19 infections.

The policy starts to reduce the number of COVID-19 infections around 20 days after implementation.

School closures continue to reduce the number of new cases for as much as 100 days after the initiation of the policy.

Vincenzo Alfano

valfano@wiut.uz

1 Department of Economics, Westminster International University in Tashkent, Tashkent, Uzbekistan

2 Center for Economic Studies of Munich, CES-ifo, Munich, Germany

\section{Introduction and Research Question}

Beginning in December 2019, a new coronavirus infectious disease (COVID-19) spread rapidly around the world [1]. For this reason, on 11 March 2020, the World Health Organization (WHO) declared COVID-19 a pandemic. According to WHO data, at least 215 countries, areas or territories have reported confirmed cases of infection, making it a global emergency. It should be noted that the situation is rapidly evolving, making it difficult to provide precise figures about the unfolding of the pandemic. While the intensity of the pandemic has changed both over time and across countries, over the course of 2020 and 2021 almost every government in the world has taken measures to mitigate its effects and protect their citizens' health.

Nevertheless, these policies are very different; indeed, there have been very heterogeneous approaches to the 
issue from different authorities around the world [2]. The literature has already suggested dividing these policies into two large groups [3]: measures that rely on drug administration, and those that are non-pharmaceutical in nature.

While the first group of policies is aimed at strengthening the capacity of the health system to deal with the effects of COVID-19, the latter aims to ease the burden on the health system by reducing the probability of contracting the virus for all citizens, in a way not dissimilar in spirit to the first remedies adopted by public authorities to fight the spread of viruses in the Middle Ages [4]. In this group of remedies, we find policies such as lockdowns and other social distancing measures.

The implementation of social distancing policies in numerous countries, of varying degrees of strictness, has fostered a debate about the need for such measures. However, there has been strong resistance from some stakeholders and certain policymakers about implementing them. The most likely reason is that social-distancing policies typically come with a very high economic price, characterized by the necessary shrinking or even halting of many productive activities. For this reason too, there is a rapidly growing branch of the literature in the social sciences that aims to address the efficacy of such policies. Alfano and Ercolano [3], adopting a cross-country perspective, have assessed the efficacy of lockdown measures in containing the diffusion of the virus. The authors suggest that, on average, the efficacy of lockdown in reducing new cases lasts from 7 to at least 20 days after implementation. Other scholars, like Sarwar and Sarwar [5], examining the Indian situation, and adopting a within-country perspective, suggest that the efficacy varies depending on the province. Similar results have been reached using a predictive mathematical study [6]. It has also been suggested that stocks of social capital in the population [7] and quality of government [8] play a role in this relationship.

Nevertheless, the debate is far from over. Both the World Health Organization (WHO) and some previous contributions in the literature, focusing on the Chinese case [9, 10], have highlighted the importance of social-distancing measures in reducing the probability of contagion (and thus the related diffusion of the virus). Regardless, the political debate appears to have been greatly influenced by the effect of those measures on national economies. The public and some politicians often focus on the potential ineffectiveness of this kind of policy, and also on the estimation of a good trade-off between safeguarding citizens' health and avoiding damage to the economy.

A peculiar case in this group of policies is the closure of schools. This was one of the first policies adopted by governments facing the pandemic, and has been among the most widely adopted, and amply debated.

The evidence of its efficacy comes mainly from previous experience with influenza [11]. Some studies suggest that it is neither necessary nor useful to close schools if certain policies are adopted [12]. On the other hand, some authors suggest that school closures might be effective insofar as they force parents to work at home, reducing the spread of the virus in workplaces [13]. According to Viner and his coauthors, no fewer than 107 countries implemented national school closures by 18 March 2020 [14], making it the most widely adopted policy to fight coronavirus.

Some studies $[15,16]$ report that the first school closures were imposed nationally across mainland China in late January 2020, making it one of the earliest policies to be implemented. This was part of a broader series of control measures during that country's COVID-19 epidemic. However, no data are available regarding the effectiveness of school closures, as there was little variation in the timing of closures [14], and, as we have said, school closures were part of a larger set of policies that included a broad range of quarantine and social-distancing measures.

It remains unknown whether this measure is effective in reducing the spread of COVID-19. Previous modelling studies based on SARS produced conflicting results [17], while COVID-19 modelling predicts that school closures prevent $2-4 \%$ of deaths [14]. This reduction rate is much lower than with other social-distancing measures. Policymakers have often found it hard to decide when to re-open schools, as further testified by outbreaks a few days after the reopening of schools in Israel [18] and, according to evidence from last year, in Italy [19].

It is also important to highlight that, like lockdowns, school closures are accompanied by an economic cost. Indeed, school closures come with many trade-offs, and can create unintended child-care obligations. It has been estimated that mandatory school closure has increased the infection mortality rate in the USA from 2 to $2.35 \%$ [11], due to the childcare duties of health workers. Moreover, according to Azevedo et al. [20], the decision to keep schools closed adversely affected educational outcomes, and is likely to cause a reduction in future earnings. Similar findings have been obtained for Italy in the work of Cucco et al. [21], who also find evidence of an adverse impact of school closures on schooling drop-out rates.

For all these reasons, it is important to test the effectiveness of school closures in reducing contagion empirically. While some contributions address this topic, to the best of our knowledge the principal empirical papers that focus specifically on the efficacy of school closures have been carried out at national level. Cowling and his co-authors [22], in studying the situation in Hong Kong, conclude that a 4-week school closure initiated on 1 February helped to reduce 
infections, together with other measures implemented. The community transmission reduced estimate is $44 \%$, much more than the $10-15 \%$ estimated for influenza during the 2009 pandemic in Hong Kong [23]. However, in that case too, as with mainland China, the authors were unable to separate the effects of school closures from other measures.

To the best of our knowledge, only one study has been devoted specifically to examining the effect of school closures separately from other non-pharmaceutical policies: that of Ferguson and his co-authors [24], which, using UK population and schools' data with COVID-19 transmission dynamics from Wuhan, concludes that school closures as an isolated measure reduced total deaths by $2-4 \%$ in the UK outbreak, although they were insufficient to mitigate the COVID-19 pandemic on their own.

Following the recent literature on this topic [3, 19, 25], the aim of this paper was to provide empirical evidence regarding the efficacy of school-closure measures in reducing case numbers in the COVID-19 outbreak by means of quantitative analysis, namely a panel data approach. It is of course difficult, given different seasons and thus different school breaks around the world, to approach this research question in a cross-country perspective. Accordingly, since the school year is of different lengths around the world and, more importantly, begins at different times of the year, we decided to focus on Europe. We consider this choice appropriate for two principal reasons. First, unlike other continents, Europe is relatively compact, with a smaller difference in climate among its various states, which on the same dates are at least in the same seasons. Second, Europe is densely populated and has been hit hard by COVID-19, and thus offers an important source of heterogeneity for the purposes of our study. Finally, it is also important to note that in the European continent school years are much more similar than those in the rest of the world [26]. This allows us to get rid of potential biases in the estimates due to a reverse causality. Indeed, while the unfolding of the pandemic has certainly played a role in the decision to close schools, at the same time schools are closed in Europe over summer each year, offering a time in which the choice to keep schools closed is independent from the dynamic of infections.

As we have seen, many studies focus on the impact of a given policy in terms of reducing deaths. While this may be the optimal choice in a country-level study, heterogeneity among countries makes it inapplicable in a cross-country perspective. Populations belonging to very different age cohorts, with different life expectancies and different hospital systems, make it hard to disentangle all the variables, and thus to infer whether a certain number of people died because of one reason rather than another. On the other hand, the number of cases, while certainly affected by the testing policies, should be more orthogonal than other variables, and thus unrelated and more appropriate for use in a cross-country study.

More specifically, in the present work we address three different research questions, namely:

1. Is there cross-country empirical evidence on the effectiveness of school-closure measures in reducing COVID19 case numbers?

2. How long does it take for school closures to become effective in reducing cases?

3. How long does it take for this measure to lose its effectiveness?

This approach allowed us to observe and take into account heterogeneity within different countries, without comparing cases that are too structurally different, and thus incomparable. It is important to observe that these kinds of results, while less useful for the detection of a precise estimation at country level, allow us to generalize a complex phenomenon, and to benefit from a statistical point of view from a higher number of observations, which allows us to add robustness to the results.

\section{Data and Methods}

To pursue our objectives, we utilize a panel dataset, with daily data from 40 different countries in Europe used as the basic statistical unit of observation. In formal terms, in order to answer our research questions, we estimate the following equation:

$\Delta i_{c t}=\alpha+\beta_{1} i_{c t-1}+\beta_{2} D S C_{c t}+\beta_{3} S T R_{c t}+\varepsilon$,

where $\Delta i$ are new COVID-19 cases at time $t$ with respect to $t-1$ in country c. This is modelled, following the most recent literature $[3,7,8,25]$, as a function of the total number of cumulative confirmed cases from the start of the pandemic up to and including yesterday in country $c$ the previous day $\left(i_{t-1}\right)$. Furthermore, the equation includes two other variables (as well as the usual error term $\varepsilon$ ):

1. DSC, a dichotomous dummy variable that signals whether or not on the day $t$ there was a school closure in place in country $c . D S C$ may also signal which country had schools closed for $x$ days (more details on this are given below), in order to control for the time effectiveness of the policy. To clarify, in this alternative operationalization, $D S C$ assumes value 1 if schools were closed for at least $x$ consecutive days up to and including $t$, and assumes 0 otherwise;

2. STR, a dummy signalling the overall stringency of antiCOVID-19 measures in place in country $c$ on day $t$, in 
order to capture variance in $\Delta i$ due to policies other than school closures, and avoid biased estimates of the coefficients.

To estimate our equation, we need: (1) the daily number of COVID-19 cases for each $c$ and $t$; (2) data on the schools closed in each $c$ and $t$; and (3) an index measuring all the measures taken to fight the virus in each $c$ and $t$. We gathered all these data from the Oxford COVID-19 Government Response Tracker (henceforth0 OxCGRT [27]) dataset, compiled from publicly available information by a cross-disciplinary Oxford University team of academics and students from every part of the world, led by the Blavatnik School of Government [28], in its latest version available on 1 October 2020.

The OxCGRT offers a number of variables useful for our purposes: first of all, a daily estimation of COVID-19 cases from 1 January 2020 up to 30 September 2020 from all over the world. The time frame is justified by the need to focus on one COVID-19 wave and on a more homogeneous period, in terms of knowledge of the virus, presence of vaccines and other latent variables that may affect this relationship. Due to our focus on Europe, 40 different countries are included in our final sample. ${ }^{1}$ From this source, we computed our dependent variable New Cases, the operationalization of $\Delta i$, as the first difference for each country $c$ between the cases of today and those of yesterday; and also one of the independent variables, YCases, the operationalization of $i_{t-1}$, which is for each day the total number of cumulative COVID-19 cases reported up to and including yesterday, for each country $c$.

In order to discriminate between open and closed schools for each country and day, we also rely on OxCGRT, which reports school closures in its $\mathrm{C} 1$ indicator. This allows us to distinguish between countries that had schools closed on day $t$, and countries that did not, and to build the dichotomous variable SchoolClosure, operationalization of $D S C_{c t}$. This variable assumes the value of 1 for each country $c$ on the days on which schools were closed (i.e., when a country implemented a partial or a complete school-closure measure for its population, or when there was a break season and thus the schools were closed).

We also operationalized $D S C$ in an alternative way, making it equal to one only if a school was closed for a given number of consecutive days. Indeed, $97.5 \%$ of those who develop symptoms of COVID-19 do so within 11.5 days of

\footnotetext{
1 These are: Albania, Andorra, Austria, Belarus, Belgium, Bosnia and Herzegovina, Bulgaria, Croatia, Cyprus, the Czech Republic, Denmark, Estonia, Finland, France, Germany, Greece, Hungary, Iceland, Ireland, Italy, Kosovo, Latvia, Lithuania, Luxembourg, Moldova, the Netherlands, Norway, Poland, Portugal, Romania, San Marino, Serbia, the Slovak Republic, Slovenia, Spain, Sweden, Switzerland, Turkey, Ukraine and the United Kingdom.
}

infection, with a $95 \%$ confidence interval of between 8.2 and 15.6 days [29]. In other words, this suggests that there is a certain delay in place between infection and the possibility of symptomatic patients being tested positive. For this reason, all the social distancing measures (to which school closure belongs) may imply greater benefits in terms of a reduction in new cases only after the elapse of a certain time after the implementation of the policy. Accordingly, we created a set of variables labelled After $x$ days, which measures the impact of a certain $x$ number of days of school closure on New Cases.

Finally, OxCGRT also offers the Oxford Stringency Index, a measure of the policies implemented in order to fight COVID-19 in each country $c$ for each day $t$. It is calculated as the sum of several different sub-indexes, then rescaled in a $0-100$ base. This index, according to its creators, "records the strictness of 'lockdown style' policies that primarily restrict people's behaviour. It is calculated using all ordinal containment and closure policy indicators, plus an indicator recording public information campaigns". ${ }^{2}$

This is a proxy of all the other policies that may impact on our dependent variable New Cases, other than school closures, already used in the literature [25]. More precisely, this index takes into account workplace closures, cancellations of public events, restrictions on the size of gatherings, closures of public transportation, home confinement orders, and restrictions on internal and international travel. All things considered, this seems to be a good approximation for taking into account and controlling for other policies that may affect the outbreak of the coronavirus.

Considering that data have several observations for each $c$ and $t$, the most efficient estimator is a Feasible-Generalized Least Square (F-GLS) [30, 31]. Also, taking into account that the spread of the virus may be due to several factors specific to each country (such as culture, climate, relative wealth, and so on), from a theoretical perspective we consider it more appropriate to employ a Fixed Effects (FE) estimator, which captures time-invariant heterogeneity between countries. In other words, in this way it is possible to estimate the average effects for single countries, assuming that the heterogeneity among them does not change in our timespan. At the same time, it is important to recognize that controlling for these time-invariant country-specific fixed effects removes much of the bias from the overall estimate of the impact of school closures. This also implies that all the variables that vary by country but not over time (i.e., that are time-invariant) do not affect our estimation. A Hausman test [32] (reported in Table 1) also suggests weak evidence from an empirical point of view in favour of a FE estimator.

\footnotetext{
2 https://www.bsg.ox.ac.uk/research/research-projects/covid-19government-response-tracker (URL consulted on 23/09/2021).
} 
Table 1 Hausman test for fixed versus random effects, baseline model (SchoolClosure)

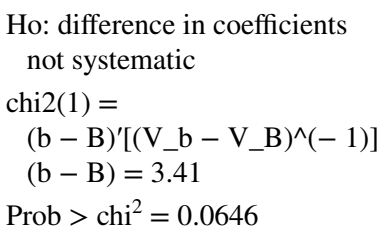

While estimation of dynamic panel models with fixed effects may be biased [33], the fact that our dataset has a very long time span ( $t$ is 274 ) gives us reasonable confidence about the robustness of the estimates.

Our final dataset is composed of 274 daily observations (from 1 January to 30 September) in 40 countries, giving a total of 10,960 observations. Descriptive statistics of the variables are presented in Table 2, with variables also decomposed into between-country and within-country components.

\section{Results}

Results of the estimates through an F-GLS-FE on the complete sample are presented in Table 3 analytically and in Fig. 1 graphically. YCases is the operationalization of $i_{c t-1}$, and is the total cumulative number of COVID-19 cases registered in country $c$ on $t-1$ (i.e., up to, and including, yesterday). It has, as expected, a positive and statistically significant coefficient, suggesting that the more total confirmed cumulative cases there were reported yesterday, the more New Cases of COVID-19 there will be today. Figure 1 shows the effect up to 100 days after closing, showing how the impact of school closure tends to increase over time, in line with the exponential nature of the pandemic, up to a certain threshold, after which it starts to diminish, as the benefits of this policy begin to decline.

Our main variable of interest, SchoolClosure, starts to have a negative and statistically significant coefficient only 20 days after closing schools, suggesting that on average countries that implemented this policy have fewer New Cases than countries that did not after this threshold of days. Thus, as expected, the beneficial effects of this policy are not immediate, since some days have to pass before the lack of

Table 2 Descriptive statistics

\begin{tabular}{|c|c|c|c|c|c|c|c|}
\hline Label variable & Variable & Mean & Sample & SD & Min. & Max. & Observations \\
\hline NewCases & $\begin{array}{l}\text { First difference between total cumulative } \\
\text { confirmed COVID-19 cases on } t \text { and } \\
t-1\end{array}$ & 374.7646 & $\begin{array}{l}\text { Overall } \\
\text { Between countries } \\
\text { Within countries }\end{array}$ & $\begin{array}{l}1221.116 \\
609.6051 \\
1062.433\end{array}$ & $\begin{array}{l}-1385 \\
2.653285 \\
-3145.491\end{array}$ & $\begin{array}{l}31,785 \\
2807.255 \\
29,352.51\end{array}$ & $\begin{array}{l}\mathrm{N}=10,960 \\
\mathrm{n}=40 \\
\mathrm{~T}=274\end{array}$ \\
\hline YCases & $\begin{array}{l}\text { Total cumulative confirmed COVID-19 } \\
\text { cases on } t-1\end{array}$ & 33858.93 & $\begin{array}{l}\text { Overall } \\
\text { Between countries } \\
\text { Within countries }\end{array}$ & $\begin{array}{l}75,960.91 \\
54,615.18 \\
53,493.42\end{array}$ & $\begin{array}{l}0 \\
438.2555 \\
-175,883.9\end{array}$ & $\begin{array}{l}75,8172 \\
209,742.8 \\
582,288.1\end{array}$ & $\begin{array}{l}\mathrm{N}=10,960 \\
\mathrm{n}=40 \\
\mathrm{~T}=274\end{array}$ \\
\hline Stringency & $\begin{array}{l}\text { Oxford Stringency Index, measuring on } \\
\text { a } 0-100 \text { scale the level of stringency } \\
\text { within a country }\end{array}$ & 42.7531 & $\begin{array}{l}\text { Overall } \\
\text { Between countries } \\
\text { Within countries }\end{array}$ & $\begin{array}{l}28.45154 \\
8.896993 \\
27.06114\end{array}$ & $\begin{array}{l}0 \\
9.116788 \\
-11.37828\end{array}$ & $\begin{array}{l}100 \\
54.13139 \\
99.14361\end{array}$ & $\begin{array}{l}\mathrm{N}=10960 \\
\mathrm{n}=40 \\
\mathrm{~T}=274\end{array}$ \\
\hline SchoolClosure & $\begin{array}{l}\text { Dichotomous dummy variable, equal to } 1 \\
\text { if schools are closed, to } 0 \text { otherwise }\end{array}$ & .5398723 & $\begin{array}{l}\text { Overall } \\
\text { Between countries } \\
\text { Within countries }\end{array}$ & $\begin{array}{l}.4984304 \\
.2116052 \\
.4525169\end{array}$ & $\begin{array}{l}0 \\
.0583942 \\
-.2338504\end{array}$ & $\begin{array}{l}1 \\
.7737226 \\
1.481478\end{array}$ & $\begin{array}{l}\mathrm{N}=10960 \\
\mathrm{n}=40 \\
\mathrm{~T}=274\end{array}$ \\
\hline After 10 days & $\begin{array}{l}\text { Dichotomous dummy variable, equal to } \\
1 \text { if schools are closed since at least } 10 \\
\text { days, to } 0 \text { otherwise }\end{array}$ & .5611314 & $\begin{array}{l}\text { Overall } \\
\text { Between countries } \\
\text { Within countries }\end{array}$ & $\begin{array}{l}.4962715 \\
.2058096 \\
.4527505\end{array}$ & $\begin{array}{l}0 \\
.0218978 \\
-.1760949\end{array}$ & $\begin{array}{l}1 \\
.7372263 \\
1.539234\end{array}$ & $\begin{array}{l}\mathrm{N}=10960 \\
\mathrm{n}=40 \\
\mathrm{~T}=274\end{array}$ \\
\hline After 20 days & $\begin{array}{l}\text { Dichotomous dummy variable, equal to } \\
1 \text { if schools are closed since at least } 20 \\
\text { days, to } 0 \text { otherwise }\end{array}$ & .525 & $\begin{array}{l}\text { Overall } \\
\text { Between countries } \\
\text { Within countries }\end{array}$ & $\begin{array}{l}.4993974 \\
.2048395 \\
.4566002\end{array}$ & $\begin{array}{l}0 \\
0 \\
-.1757299\end{array}$ & $\begin{array}{l}1 \\
.7007299 \\
1.419161\end{array}$ & $\begin{array}{l}\mathrm{N}=10960 \\
\mathrm{n}=40 \\
\mathrm{~T}=274\end{array}$ \\
\hline After 30 days & $\begin{array}{l}\text { Dichotomous dummy variable, equal to } \\
1 \text { if schools are closed since at least } 30 \\
\text { days, to } 0 \text { otherwise }\end{array}$ & .4894161 & $\begin{array}{l}\text { Overall } \\
\text { Between countries } \\
\text { Within countries }\end{array}$ & $\begin{array}{l}.4999108 \\
.2025091 \\
.4581729\end{array}$ & $\begin{array}{l}0 \\
0 \\
-.1748175\end{array}$ & $\begin{array}{l}1 \\
.6642336 \\
1.420073\end{array}$ & $\begin{array}{l}\mathrm{N}=10960 \\
\mathrm{n}=40 \\
\mathrm{~T}=274\end{array}$ \\
\hline After 40 days & $\begin{array}{l}\text { Dichotomous dummy variable, equal to } \\
1 \text { if schools are closed since at least } 40 \\
\text { days, to } 0 \text { otherwise }\end{array}$ & .4538321 & $\begin{array}{l}\text { Overall } \\
\text { Between countries } \\
\text { Within countries }\end{array}$ & $\begin{array}{l}.4978867 \\
.2003178 \\
.4569065\end{array}$ & $\begin{array}{l}0 \\
0 \\
-.1739051\end{array}$ & $\begin{array}{l}1 \\
.6277372 \\
1.420985\end{array}$ & $\begin{array}{l}\mathrm{N}=10960 \\
\mathrm{n}=40 \\
\mathrm{~T}=274\end{array}$ \\
\hline
\end{tabular}

$S D$ standard deviation, min. minimum, max. maximum 
Table 3 Feasible-generalised least-squares fixed-effect estimation-New Cases on explanatory variables—without Stringency Index

\begin{tabular}{|c|c|c|c|c|c|}
\hline & New Cases & & & & \\
\hline YCases & $0.00837^{* * * *}(48.41)$ & $0.00847^{* * * *}(46.89)$ & $0.00889^{* * *}(48.64)$ & $0.00929^{* * * *}(50.57)$ & $0.00958^{* * * *}(52.09)$ \\
\hline SchoolClosure & $163.5^{* * *}(8.00)$ & & & & \\
\hline After 10 days & & $36.60^{*}(1.71)$ & & & \\
\hline After 20 days & & & $-107.9^{* * *}(-5.04)$ & & \\
\hline After 30 days & & & & $-226.8^{* * * *}(-10.58)$ & \\
\hline After 40 days & & & & & $-309.2^{* * *}(-14.37)$ \\
\hline Constant & $3.242(0.22)$ & $67.45^{* * *}(4.56)$ & $130.5^{* * *}(9.22)$ & $171.4^{* * *}(12.64)$ & $190.8^{* * * *}(14.63)$ \\
\hline Observations & 10960 & 10960 & 10960 & 10960 & 10960 \\
\hline
\end{tabular}

$t$ statistics in parentheses

${ }^{*} p<0.1, * * p<0.05, * * * p<0.01$

Fig. 1 The horizontal axis measures the value for the different betas of several school closure dummies, computed at the date of implementation of the policy, 7 days after, 8 days after, and so on, up to 100 days after (measured on the vertical axis). Lines and lighter colours represent $95 \%$ and $90 \%$ confidence intervals. Betas are estimated through the feasiblegeneralised least-squares fixed-effect (F-GLS-FE) model, not including the variable stringency in the regression

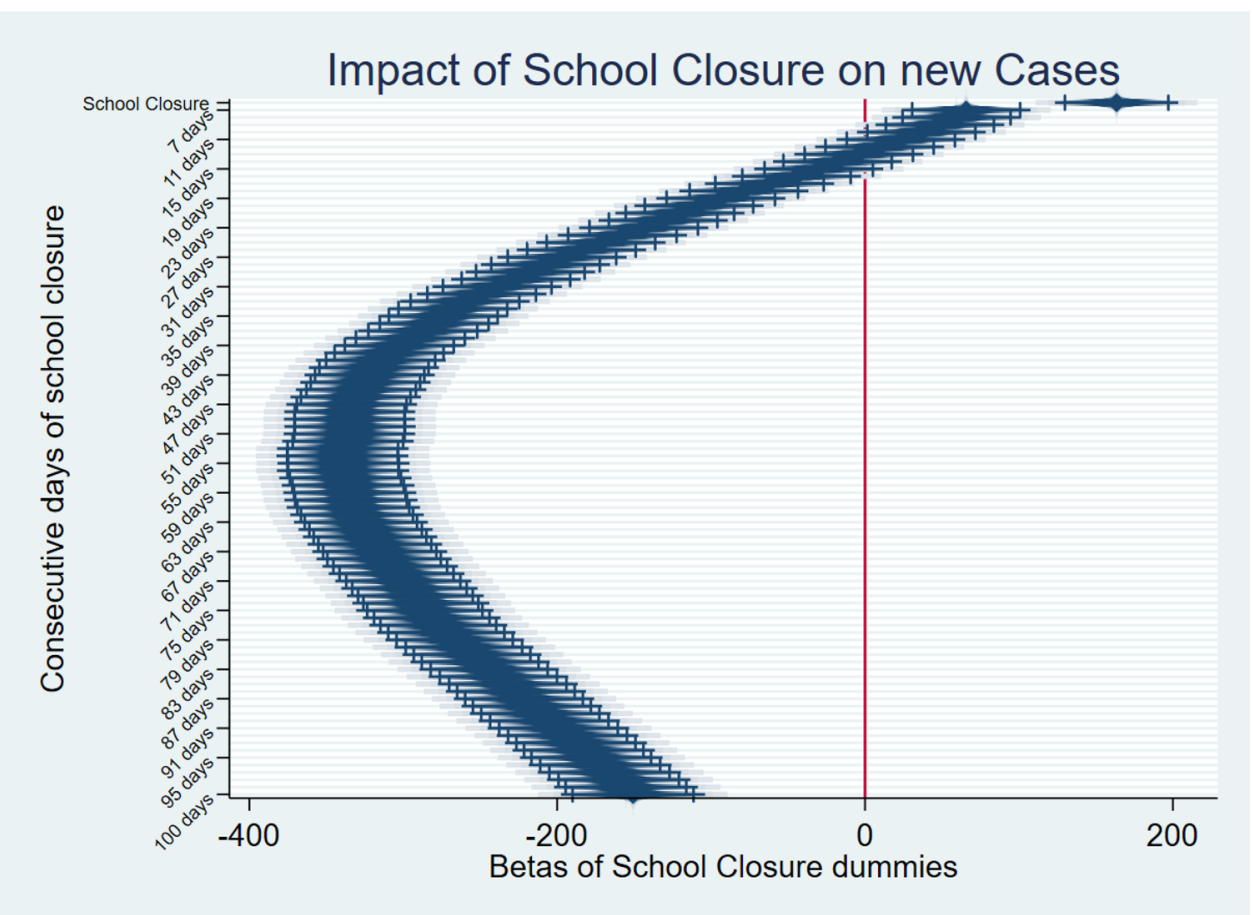

new contagions appears in the data. We can also see, looking at the magnitude of the coefficients, that the benefits of this policy increase with the passing of time, up to 40 days after school closures.

Looking at Table 4, these results also hold when controlling for the variable Stringency by including it in the regression. As explained, this is an index proxying all the measures put in place by the government to fight the pandemic. This suggests that school closures are effective in reducing the spread of COVID-19 even when controlling for other nonpharmaceutical interventions in place. The effect becomes even faster when controlling for it, and becomes statistically significant 10 days after the school closure.

But how long do the benefits of having schools closed last? In Fig. 2, we replicated the previous analysis, plotting the betas of the SchoolClosure variable computed for up to 100 days after the implementation of the policy, also including in the regression the variable Stringency in order to control for the implementation of other non-pharmaceutical interventions in place in the various countries. As can be seen, after about 40 days of closing schools the policy has its maximum impact on new COVID-19 cases, and after about 100 days this effect, even if less strong, is still present and statistically significant.

While both theory and a Hausman test suggested that FE would be a better estimator than RE, we cannot assume that all school closures are equal among the 40 different countries included in the analysis. Furthermore, these measures may have occurred at different times, and thus vary considerably between countries or between different 
Table 4 Feasible-generalised least-squares fixed-effect estimation—New Cases on explanatory variables—with Stringency Index

\begin{tabular}{|c|c|c|c|c|c|}
\hline & New cases & & & & \\
\hline YCases & $0.00816^{* * *}(46.53)$ & $0.00849^{* * *}(47.39)$ & $0.00887^{* * * *}(49.18)$ & $0.00916^{* * *}(50.58)$ & $0.00934^{* * *}(51.34)$ \\
\hline SchoolClosure & $10.11(0.33)$ & & & & \\
\hline Stringency & $3.471^{* * * *}(6.63)$ & $6.599^{* * *}(13.25)$ & $7.432^{* * *}(17.17)$ & $7.117^{* * * *}(18.17)$ & $6.379^{* * * *}(17.37)$ \\
\hline After 10 days & & $-255.2^{* * *}(-8.35)$ & & & \\
\hline After 20 days & & & $-387.0^{* * *}(-14.52)$ & & \\
\hline After 30 days & & & & $-443.4^{* * * *}(-18.28)$ & \\
\hline After 40 days & & & & & $-459.6^{* * *}(-20.04)$ \\
\hline Constant & $-55.31^{* * *}(-3.20)$ & $-51.71^{* * *}(-3.00)$ & $-40.07^{* *}(-2.34)$ & $-22.62(-1.32)$ & $-5.567(-0.32)$ \\
\hline Observations & 10960 & 10960 & 10960 & 10960 & 10960 \\
\hline
\end{tabular}

$t$ statistics in parentheses

$* p<0.1, * * p<0.05, * * * p<0.01$

Fig. 2 The horizontal axis measures the value for the different betas of several school closure dummies, computed at the date of implementation of the policy, 7 days after, 8 days after, and so on, up to 100 days after (measured on the vertical axis). Lines and lighter colours represent $95 \%$ and $90 \%$ confidence intervals. Betas are estimated through the feasiblegeneralised least-squares fixed-effect (F-GLS-FE) model, including the variable stringency in the regression

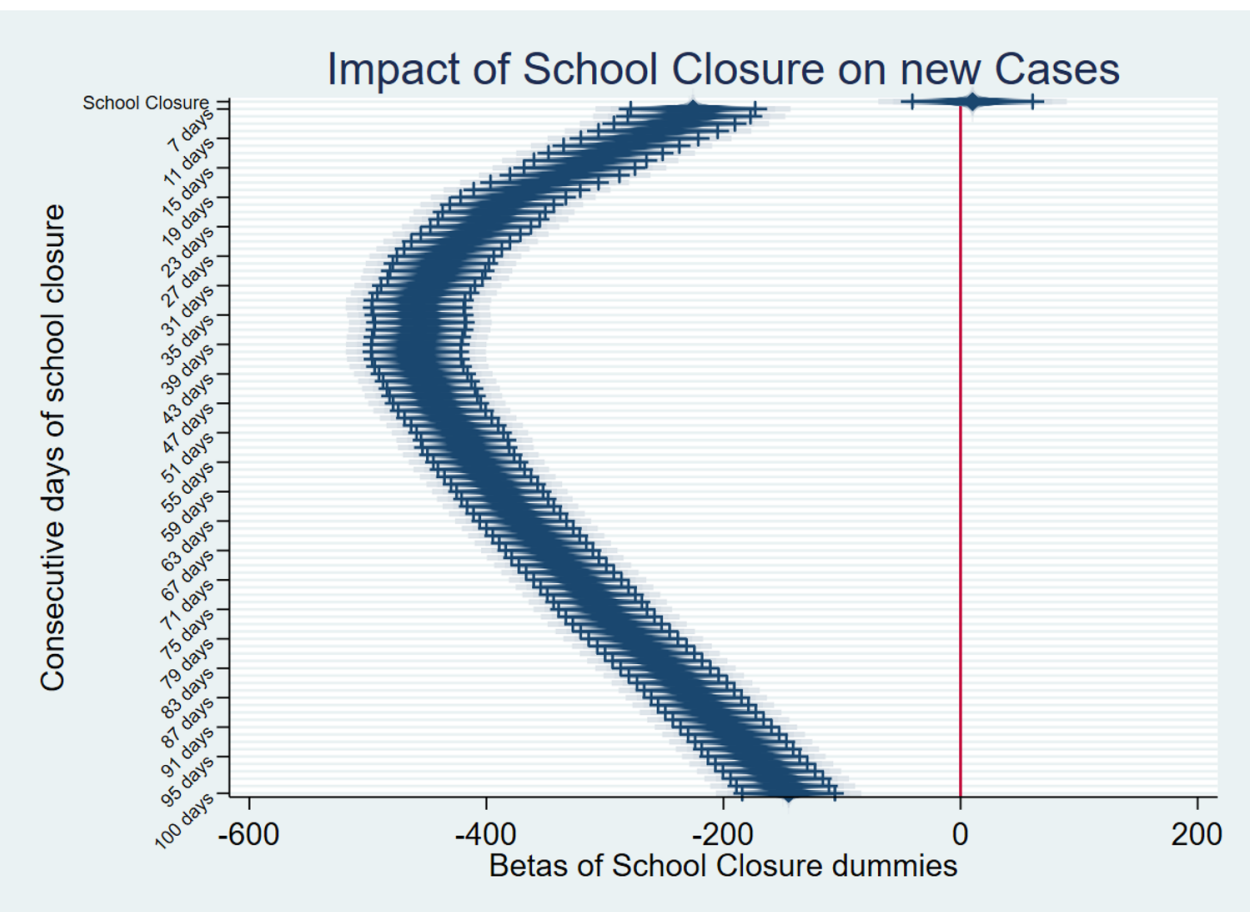

European geographical regions. For these reasons, we also estimated Equation 1 through an F-GLS Random Effects estimator. Results are included in Table 5 (without including the Oxford Stringency Index in the regression) and Table 6 (including it), and are perfectly compatible with the previous finding, suggesting some robustness in the results.

Furthermore, we also re-estimated the model through a hierarchical linear random effects analysis of variance (ANOVA) [34]. Results are presented in Table 7 (without the Oxford Stringency Index), and Table 8 (including the index). This family of models allows us to analyse the degree of variance due to cross-regional differences. We followed the distinction adopted by the United Nations Statistical Department $^{3}$ to divide Europe into regions. The regions identified in this taxonomy are: Eastern Europe (25\% of the sample), Northern Europe (25\%), Southern Europe (32.50\%), and Western Europe (17.50\%). As expected, the likelihood ratio test statistics for the null hypothesis that there is no crossregional variation in New Cases have a p-value of 0.0001, suggesting that there is indeed variation between the regions identified. Looking at the coefficients, these results are also in line with the previous estimates, suggesting once again some robustness in our findings across Europe.

\footnotetext{
3 As reported in https://unstats.un.org/unsd/methodology/m49/ (URL consulted on 23/09/2020).
} 
Table 5 Feasible-generalised least-squares random-effect estimation-New Cases on explanatory variables-without Stringency Index

\begin{tabular}{|c|c|c|c|c|c|}
\hline & New cases & & & & \\
\hline YCases & $\begin{array}{c}0.00856^{* * * *} \\
(51.76)\end{array}$ & $\begin{array}{c}0.00866^{* * *} \\
(50.26)\end{array}$ & $0.00905^{* * *}(51.94)$ & $\begin{array}{c}0.00941^{* * * *} \\
(53.78)\end{array}$ & $\begin{array}{c}0.00967^{* * * *} \\
(55.23)\end{array}$ \\
\hline SchoolClosure & $\begin{array}{c}158.1^{* * * *} \\
(7.82)\end{array}$ & & & & \\
\hline After 10 days & & $29.63(1.41)$ & & & \\
\hline After 20 days & & & $-111.9^{* * *}(-5.30)$ & & \\
\hline After 30 days & & & & $\begin{array}{r}-228.1^{* * *} \\
(-10.78)\end{array}$ & \\
\hline After 40 days & & & & & $\begin{array}{r}-308.4^{* * *} \\
(-14.53)\end{array}$ \\
\hline Constant & $\begin{array}{c}-0.447 \\
(-0.01)\end{array}$ & $64.78^{* *}(1.98)$ & $127.2^{* * * *}(3.92)$ & $167.8^{* * *}(5.21)$ & $\begin{array}{c}187.2^{\text {**** }} \\
(5.85)\end{array}$ \\
\hline Observations & 10960 & 10960 & 10960 & 10960 & 10960 \\
\hline
\end{tabular}

$t$ statistics in parentheses

${ }^{*} p<0.1, * * p<0.05, * * * p<0.01$

Table 6 Feasible-generalised least-squares random-effect estimation-New Cases on explanatory variables-with Stringency Index

\begin{tabular}{|c|c|c|c|c|c|}
\hline & New cases & & & & \\
\hline YCases & $0.00835^{* * *}(49.61)$ & $0.00865^{* * *}(50.52)$ & $0.00899^{* * *}(52.21)$ & $0.00926^{* * *}(53.54)$ & $0.00943^{* * *}(54.27)$ \\
\hline SchoolClosure & $7.555(0.25)$ & & & & \\
\hline Stringency & $3.441^{* * *}(6.62)$ & $6.611^{* * * *}(13.35)$ & $7.421^{* * * *}(17.21)$ & $7.105^{* * *}(18.19)$ & $6.371^{* * *}(17.39)$ \\
\hline After 10 days & & $-259.9^{* * *}(-8.62)$ & & & \\
\hline After 20 days & & & $-388.5^{* * * *}(-14.75)$ & & \\
\hline After 30 days & & & & $-443.4^{* * *}(-18.49)$ & \\
\hline After 40 days & & & & & $-459.0^{* * * *}(-20.25)$ \\
\hline Constant & $-59.01^{*}(-1.72)$ & $-55.02(-1.61)$ & $-43.08(-1.26)$ & $-25.52(-0.75)$ & $-8.514(-0.25)$ \\
\hline Observations & 10960 & 10960 & 10960 & 10960 & 10960 \\
\hline
\end{tabular}

$t$ statistics in parentheses

$* p<0.1, * * p<0.05, * * * p<0.01$

\section{Discussion}

This paper provides the first empirical evidence from a cross-country perspective about the effectiveness of school closures in Europe in fighting the COVID-19 outbreak. Our results confirm that in Europe school closures have had a positive impact (in terms of reduction of cases) on the pandemic, and are able to reduce the number of COVID-19 cases in the countries that implemented them. This result is robust to several estimators and different specifications of the model, including an index of stringency to take into account all the alternative and concurrent measures adopted to reduce the outbreak. It is worth noting that, as pointed out previously, our results are robust to different kinds of estimators (namely F-GLS, both with fixed effects and random effects, and ANOVA mixed models).

All these results contribute to the current debate about the importance of this type of policy, which is far from being over. While previous results suggested both the low effectiveness of school closures in some specific country contexts [14], and an important role played by opening schools in the spread of the contagion [19], our findings suggest that school closures do have a degree of impact on the spread of the pandemic. We have proven that from a cross-country perspective (and thus talking about 'on average' and 'in Europe' results), school closures are effective in reducing new COVID-19 cases.

More specifically, the effectiveness of this policy is detectable after about 20 consecutive days of school closures, and the resultant reduction in the number of COVID-19 infections continues to increase up to at least 40 days later. It still has an effect after 100 days. Accordingly, it seems that any decision to re-open schools should be considered very carefully if the full benefits of the measure in terms of reducing new cases are to be enjoyed. More importantly, a rushed re-opening of schools may render hard-won results to waste. 
Table 7 Hierarchical linear model, ANOVA random effects—New Cases on explanatory variables—without Stringency Index

\begin{tabular}{|c|c|c|c|c|c|}
\hline & New cases & & & & \\
\hline YCases & $0.00984^{* * * *}(73.03)$ & $0.00980^{* * *}(72.18)$ & $0.00990^{* * *}(72.81)$ & $0.00999^{* * * *}(73.69)$ & $0.0101^{* * * *}(74.47)$ \\
\hline Day & $-1.023^{* * *}(-7.56)$ & $-0.804^{* * *}(-5.64)$ & $-0.383^{* * *}(-2.63)$ & $0.0569(0.38)$ & $0.435^{* * *}(2.89)$ \\
\hline SchoolClosure & $178.2^{* * *}(8.72)$ & & & & \\
\hline After 10 days & & $43.25^{* *}(1.97)$ & & & \\
\hline After 20 days & & & $-105.1^{* * *}(-4.68)$ & & \\
\hline After 30 days & & & & $-237.7^{* * *}(-10.34)$ & \\
\hline After 40 days & & & & & $-339.3^{* * *}(-14.40)$ \\
\hline Constant & $91.36^{* * *}(3.39)$ & $132.2^{* * * *}(5.18)$ & $149.2^{* * * *}(5.44)$ & $145.6^{* * *}(4.87)$ & $128.0^{* * * *}(3.97)$ \\
\hline Ln SD RE & $3.586^{* * *}(7.60)$ & $3.481^{* * * *}(7.17)$ & $3.657^{* * * *}(8.26)$ & $3.822^{* * *}(9.20)$ & $3.948^{* * *}(9.85)$ \\
\hline Ln SD lev.1 & $6.894^{* * *}(1007.67)$ & $6.898^{* * *}(1008.18)$ & $6.897^{* * *}(1008.05)$ & $6.893^{* * *}(1007.47)$ & $6.888^{* * * *}(1006.79)$ \\
\hline Observations & 10686 & 10686 & 10686 & 10686 & 10686 \\
\hline
\end{tabular}

$t$ statistics in parentheses

$* p<0.1, * * p<0.05, * * * p<0.01$

Note: Ln SD is the natural logarithm of the standard deviation of respectively the Random Effect of level 2 sample (Ln SD RE), and of level 1 (Ln SD lev.1)

Table 8 Hierarchical linear model, ANOVA random effects—New Cases on explanatory variables—with Stringency Index

\begin{tabular}{|c|c|c|c|c|c|}
\hline & New cases & & & & \\
\hline YCases & $0.00966^{* * *}(70.87)$ & $0.00968^{* * *}(71.76)$ & $0.00976^{* * *}(72.58)$ & $0.00982^{* * *}(73.36)$ & $0.00987^{* * * *}(73.85)$ \\
\hline Stringency & $4.157^{* * *}(7.92)$ & $7.018^{* * *}(14.16)$ & $7.671^{* * * *}(17.46)$ & $7.310^{* * * *}(18.18)$ & $6.525^{* * * *}(17.17)$ \\
\hline Day & $-1.214^{* * *}(-8.85)$ & $-0.902^{* * *}(-6.37)$ & $-0.546^{* * *}(-3.79)$ & $-0.207(-1.41)$ & $0.0713(0.47)$ \\
\hline SchoolClosure & $14.12(0.49)$ & & & & \\
\hline After 10 days & & $-236.7^{* * *}(-8.05)$ & & & \\
\hline After 20 days & & & $-364.2^{* * *}(-13.66)$ & & \\
\hline After 30 days & & & & $-433.0^{* * * *}(-17.28)$ & \\
\hline After 40 days & & & & & $-465.6^{* * *}(-19.10)$ \\
\hline Constant & $34.16(1.28)$ & $7.818(0.26)$ & $-14.10(-0.44)$ & $-27.81(-0.83)$ & $-35.39(-1.03)$ \\
\hline Ln SD RE & $3.468^{* * *}(7.17)$ & $3.715^{* * *}(8.66)$ & $3.854^{* * *}(9.41)$ & $3.941^{* * * *}(9.85)$ & $3.994^{* * * *}(10.10)$ \\
\hline Ln SD lev.1 & $6.891^{* * *}(1007.26)$ & $6.888^{* * *}(1006.82)$ & $6.883^{* * *}(1005.99)$ & $6.877^{* * *}(1005.24)$ & $6.874^{* * *}(1004.80)$ \\
\hline Observations & 10686 & 10686 & 10686 & 10686 & 10686 \\
\hline
\end{tabular}

$t$ statistics in parentheses

Ln SD is the natural logarithm of the standard deviation of respectively the random effect of level 2 sample (Ln SD RE), and of level 1 (Ln SD lev.1)

$* p<0.1, * * p<0.05, * * * p<0.01$

As a matter of fact, our results suggest that the decision to open schools during the pandemic may easily cause a significant increase in the number of cases. It is also important to underline that our analysis is based on data from a world where vaccines were unavailable. Following widespread vaccination, it may be that school closures have quite different effects on the trend of new COVID-19 cases. Nonetheless, we believe that our results are useful even as a baseline estimation, to be compared with future estimates in a world where vaccines are available and widely distributed. For this reason, we highlight the need for more research in this field.

\subsection{Limitations}

It is important to highlight once more that we have presented a cross-country analysis, focused on the European continent. This means that it should be considered as an estimate measuring average effects for European countries. While this has many benefits in terms of generalization of the results, and provides the model with more statistical power than single-country studies (given the larger sample), there are also serious limitations in deriving precise estimates, since of course pooling countries leads to an increase in standard 
errors due to the unobservable variables and the heterogeneous treatment effect in the sample. Caution is thus suggested in reading these results, which are necessarily also driven by the timing of the measures taken in Europe, as well as by the specific unfolding of the pandemic. In this respect, it is important to highlight that we partially controlled this bias by applying a multilevel analysis, although of course there is still an important heterogeneity within the different European regions, which are agglomerates of a dozen countries. It is also important to note that a sort of reverse causality may be in play in some observations, since schools were closed because of the pandemic; although at the same time is important to note that schools in Europe close each summer.

For these reasons, we highlight the importance of and need for further investigations on this topic, which may focus on more specific territorial or climatic subsamples, or on how governments have implemented social distancing policies.

\section{Declarations}

Funding Not applicable.

Conflict of interest The author declares no conflict of interest.

Ethics approval Not applicable.

Consent to participate Not applicable.

Consent for publication (from patients/participants) Not applicable.

Availability of data and material (data transparency) All data are gathered from public sources reported in the text.

Code availability (software application or custom code) The model was shared for the peer-review process. The author can provide more details upon request.

\section{References}

1. Shao P. Impact of city and residential unit lockdowns on prevention and control of COVID-19. medRxiv. 2020.

2. Piguillem F, Shi L. The optimal covid-19 quarantine and testing policies (No. 2004). Einaudi Institute for Economics and Finance (EIEF). 2020.

3. Alfano V, Ercolano S. The efficacy of lockdown against COVID19: a cross-country panel analysis. Appl Health Econ Health Policy. 2020;18:509-17.

4. Alfano V, Sgobbi M. A Peste, Fame et Bello libera Nos, Domine. An analysis of the black death in Chioggia in 1630. J Fam Hist. 2021.

5. Sarwal R, Sarwal T. Mitigating COVID-19 with lockdowns: a possible exit strategy. Available at SSRN 3563538. 2020.

6. Sardar T, Nadim SS, Rana S, Chattopadhyay J. Assessment of lockdown effect in some states and overall India: a predictive mathematical study on COVID-19 outbreak. Chaos Solitons
Fractals. 2020;139:110078. https://doi.org/10.1016/j.chaos. 2020.110078 (Epub 2020 Jul 8. PMID: 32834620; PMCID: PMC7345298).

7. Alfano V, Ercolano S. Social capital, quality of institutions and lockdown. Evidence from Italian provinces. Struct Chang Econ Dyn. 2021;59:31-41.

8. Alfano V, Ercolano S. Stay at home! Governance quality and effectiveness of lockdown. Soc Indic Res. 2021. https://doi.org/ 10.1007/s11205-021-02742-3.

9. Figueiredo AM, Daponte Codina A, Figueiredo M, Saez M, Cabrera León A. Impact of lockdown on COVID-19 incidence and mortality in China: an interrupted time series study. Bull World Health Organ. 2020. n. E-pub: 6 April 2020. https://doi.org/10. 2471/BLT.20.256701.

10. Lau H, Khosrawipour V, Kocbach P, Mikolajczyk A, Schubert J, Bania J, Khosrawipour T. The positive impact of lockdown in Wuhan on containing the COVID-19 outbreak in China. J Travel Med. 2020.

11. Bayham J, Fenichel EP. Impact of school closures for COVID-19 on the US health-care workforce and net mortality: a modelling study. Lancet Public Health. 2020;5(5):271-8.

12. Melnik H, Darling-Hammond LD. Reopening schools in the context of COVID-19: health and safety guidelines from other countries. Learning policy Institute, Policy Brief. 2020. Retrieved at https://files.eric.ed.gov/fulltext/ED606555.pdf.

13. Rashid H, Ridda I, King C, Begun M, Tekin H, Wood JG, Booy R. Evidence compendium and advice on social distancing and other related measures for response to an influenza pandemic. Paediatr Respir Rev. 2015;16:119-26.

14. Viner RM, Russell SJ, Croker H, Packer J, Ward J, Stansfield C, et al. School closure and management practices during coronavirus outbreaks including COVID-19: a rapid systematic review. Lancet Child Adolesc Health. 2020;4(5):397-404. https://doi.org/ 10.1016/S2352-4642(20)30095-X (PMID: 32272089).

15. Tian H, Liu Y, Li Y et al. The impact of transmission control measures during the first 50 days of the COVID-19 epidemic in China. medRxiv. 2020. https://doi.org/10.1101/2020.01.30.20019 844 (preprint).

16. Lai S, Ruktanonchai NW, Zhou L, et al. Effect of non-pharmaceutical interventions to contain COVID-19 in China. Nature. 2020;585:410-3. https://doi.org/10.1038/s41586-020-2293-x.

17. Becker NG, Glass K, Li Z, Aldis GK. Controlling emerging infectious diseases like SARS. Math Biosci. 2005;193:205-21.

18. Stein-Zamir C, Abramson N, Shoob H, Libal E, Bitan M, Cardash T, Cayam R, Miskin I. A large COVID-19 outbreak in a high school 10 days after schools' reopening, Israel, May 2020. Euro Surveill. 2020. https://doi.org/10.2807/1560-7917.ES.2020.25.29. 2001352.

19. Alfano V, Cicatiello L, Ercolano S. School openings and the COVID-19 outbreak in Italy. A provincial-level analysis using the synthetic control method. Health Policy. 2021;125(9):1200-7.

20. Azevedo, et al. Simulating the potential impacts of COVID-19 school closures on schooling and learning outcomes: a set of global estimates. World Bank Res Observ. 2021;36(1):1-40.

21. Cucco B, Gavosto A, Romano B. How to fight against drop out and demotivation in crisis context: some insights and examples from Italy. In: Lecture notes in educational technology. Springer; 2021.

22. Cowling BJ, Ali ST, Ng TWY, Tsang TK, Li JCM, Fong MW, Liao Q, Kwan MY, Lee SL, Chiu SS, Wu JT, Wu P, Leung GM. Impact assessment of non-pharmaceutical interventions against coronavirus disease 2019 and influenza in Hong Kong: an observational study. Lancet Public Health. 2020;5(5):e279-88. https:// doi.org/10.1016/S2468-2667(20)30090-6 (Epub 2020 Apr 17. PMID: 32311320; PMCID: PMC7164922). 
23. Kwok KO, Wong VWY, Wei WI, Wong SYS, Tang JW. Epidemiological characteristics of the first 53 laboratory-confirmed cases of COVID-19 epidemic in Hong Kong. Euro Surveill. 2020;25(16):2000155. https://doi.org/10.2807/1560-7917.ES. 2020.25.16.2000155.

24. Ferguson NM, Laydon D, Nedjati-Gilani G, Imai N, Ainslie K, Baguelin M, Bhatia S, Boonyasiri A, Cucunubá Z, Cuomo-Dannenburg G, Dighe A, Dorigatti I, Fu H, Gaythorpe K, Green W, Hamlet A, Hinsley W, Okell LC, van Elsland S, Thompson H, Verity R, Volz E, Wang H, Wang Y, Walker PGT, Walters C, Winskill P, Whittaker C, Donnelly CA, Riley S, Ghani AC. Report 9: impact of non-pharmaceutical interventions (NPIs) to reduce COVID-19 mortality and healthcare demand. London: Imperial College; 2020. p. 2020.

25. Alfano V. Work ethics, stay-at-home measures and COVID-19 diffusion. Eur J Health Econ. 2021. https://doi.org/10.1007/ s10198-021-01402-0.

26. EURYDICE. The organisation primary and general secondary education 2019/20 — facts and figures of school time in Europe. Publications Office of the European Union. 2019. https://eacea.ec. europa.eu/national-policies/eurydice/content/organisation-schooltime-europe-primary-and-general-secondary-education-\%E2\% 80\%93-201920_en. Accessed 23 Sept 2021.

27. Hale T, Angrist N, CameronBlake E, Hallas L, Kira B, Majumdar S, Petherick A, Phillips T, Tatlow H, Webster S. Variation in government responses to COVID-19 version 7.0. Blavatnik School of
Government Working Paper. May 25, 2020; 2020. http://www.bsg. ox.ac.uk/covidtracker. Accessed 23 Sept 2021.

28. Hale T, Angrist N, CameronBlake E, Hallas L, Kira B, Majumdar S, Petherick A, Phillips T, Tatlow H, Webster S. Oxford COVID19 government response tracker, Blavatnik School of Government; 2020. http://www.bsg.ox.ac.uk/covidtracker. Accessed 23 Sept 2021.

29. Lauer SA, Grantz KH, Bi Q, Jones FK, Zheng Q, Meredith H, Azman AS, Reich NG, Lessler J. The incubation period of coronavirus disease 2019 (COVID-19) from publicly reported confirmed cases: estimation and application. Ann Intern Med. 2020;172(9):577-82. https://doi.org/10.7326/M20-0504

30. Hsiao C. Analysis of panel data. Cambridge: Cambridge University Press; 1986.

31. Aigner DJ, Balestra M. Optimal experimental design for error components models. Econometrica. 1988;56(4):955-71.

32. Hausman JA. Specification tests in econometrics. Econometrica. 1978;46:1251-71.

33. Nickell S. Biases in dynamic models with fixed effects. Econometrica. 1981;49:1417-26.

34. Raudenbush SW, Bryk AS. Hierarchical linear models: applications and data analysis methods. Thousand Oaks: Sage; 1992. 